\title{
Characteristics of black rhinoceros (Diceros bicornis) bedding sites
}

\author{
Mindy B. Rice* and Martin Jones \\ Department of Biology, John Dalton Building, Manchester Metropolitan University, Chester Street, Manchester M1 5GD, U.K.
}

\begin{abstract}
Black rhino numbers have decreased greatly since the early 1970s, primarily as a result of poaching. A recent strategy to protect rhinos in Kenya has been to establish fenced sanctuaries. This has increased the rhino population and that of other species, but problems have emerged because of limited dispersal and rising animal densities. Unfortunately, how rhino utilize habitat, especially areas called bedding sites, is not well understood. These areas provide shade and may be a critical component of rhino habitat. We measured habitat variables at bedding sites located in bedding plots and compared them with control plots at Sweetwaters Reserve, Kenya. Euclea divinorum was the most common tree in the bedding site comprising $64.3 \%$ of the vegetation. Elephant dung was significantly more likely to be found in bedding plots than in control plots which suggests that elephants and rhinos use overlapping habitats. Elephants may be causing damage to the tree species that are important for bedding sites. Resource competition between large herbivores in small reserves is likely to negatively affect the tree species. Black rhino habitat, particularly bedding sites, may be at risk and rhino numbers may decrease.
\end{abstract}

Key words: bedding sites, black rhino, conservation, enclosed reserves, habitat, management

\section{Résumé}

Le nombre de rhino noirs a beaucoup diminué depuis le début des années 1970, surtout à cause du braconnage. Une stratégie récemment appliquée au Kenya consiste à créer pour eux des sanctuaires clôturés. Ceci a permis d'augmenter la population de rhinos et celle d'autres

*Correspondence: Department of Range, Wildlife and Fisheries Management, Texas Tech University, PO Box 42125, Lubbock, TX 79409, U.S.A. E-mail: mindy.rice@ttu.edu espèces, mais des problèmes ont surgi en raison de la faible dispersion et de densités croissantes. Malheureusement, on connaît mal la façon dont les rhinos utilisent leur habitat, et spécialement les sites dits «de repos». Ces endroits fournissent de l'ombre et peuvent être une composante critique de l'habitat des rhinos. Nous avons mesuré les variables de l'habitat aux sites de repos situés dans des parcelles «de repos» et nous les avons comparés avec des sites de contrôle dans la Réserve de Sweetwaters, au Kenya. Euclea divinorum était l'arbre le plus commun dans le site de repos où il représentait $64,3 \%$ de la végétation. La présence de crottes d'éléphants était significativement plus probable dans les parcelles de repos que dans les parcelles contrôle, ce qui suggère qu'éléphants et rhinos utilisent des habitats qui se chevauchent. Il se peut que les éléphants causent des dégâts aux arbres importants pour les sites de repos. La compétition pour les ressources entre grands herbivores, dans de petites réserves, risque d'affecter négativement les espèces d'arbres. L'habitat des rhinos noirs, et particulièrement les sites de repos, pourrait être en danger, et le nombre de rhinos pourrait diminuer.

\section{Introduction}

Black rhinoceros (Diceros bicornis Linnaeus 1758) were formerly the most widespread and numerous rhino species in the world (Estes, 1991). However, since the early 1970 s, over 95\% of Africa's black rhinos have been killed by poachers for their valuable horn (Berger, 1994). The decline has gone from 70,000 in the late 1960 s to less than 3300 in 1990 and an estimated 2000 in 2000 (Kingdon, 1997; Stevens-Wood, 2000). Surprisingly, many aspects of their ecology and behaviour remain poorly known. One area lacking information is rhino habitat selection and utilization of home ranges. Understanding habitat selection is essential to identifying and protecting the important aspects of rhino habitat. 
Schenkel \& Schenkel (1969) observed that rhinos regularly seek shade under trees and bushes during the hotter parts of the day. These 'bedding sites' are found within the home range and are visited by rhinos during the daytime(Joubert \& Elo, 1971). They are easily recognized by having canopy cover, a bare earth patch and at least one entrance pathways to the bare area (Tatman, StevensWood \& Smith, 2000). These sites may be an essential element of rhino habitat, but there is little information on them.

In Kenya, one way of protecting rhinos against poaching is by establishing small reserves surrounded by fences, such as Sweetwaters Reserve. These small reserves can limit the amount of habitat available to black rhinos, restrict their dispersal and bring them into greater contact with other species (Rachlow, Kie \& Berger, 1999). It has been suggested that both elephant and giraffe compete with rhinos for Acacia trees at Sweetwaters Reserve and there is a possibility that establishment and use of bedding sites by rhinos may be affected (Birkett, 2002).

This study had two main aims. The first is to investigate the characteristics of black rhino bedding sites and in particular, to identify the characteristics of the areas in which they are located. The second is to evaluate any habitat overlap of other potentially competing species with rhino bedding sites.

\section{Methods}

\section{Study area}

The research was conducted at the Sweetwaters game reserve between 18 May and 1 August 2002. The reserve is part of the larger Ol Pejeta Ranch located in the Laikipia plateau near Nanyuki, Kenya. It is surrounded by a fence and has an area of $93 \mathrm{~km}^{2}$. It was set up in 1989 with the aim of protecting black rhinos translocated from other sanctuaries in the area. Low breeding, agonistic behaviour and accidental deaths led to a decline of 6\% per annum between 1989 and 1993 (Stevens-Wood, 2000). This could have been due to the acclimatization of translocated individuals establishing their territories and dominance in a new area (Hall-Martin \& Penzhorn, 1977). The population is now gradually increasing; from the original sixteen individuals introduced in 1989, the reserve now contains twenty-five known black rhinos (Birkett, 2002).

\section{Bedding sites and bedding plots}

We joined the reserve's rangers on their daily rhino patrols and recorded all bedding sites found. Bedding sites were identified by the presence of a bare earth patch enclosed by a patch of trees providing some sort of a canopy cover as per the definition given by Tatman et al. (2000).

To investigate differences among vegetative areas, we set up fifteen $100 \mathrm{~m} \times 100 \mathrm{~m}$ plots each centered around one bedding site identified during the patrols. These plots will be called bedding plots for the rest of this paper. The bedding plots were all in mixed Euclea/Acacia habitat in three regions within the reserve: Lokichogio, Zebra and Marula (Fig. 1). There were seven plots in Zebra $\left(1.07 \mathrm{~km}^{2}\right)$ and four each in Lokichogio $\left(1.66 \mathrm{~km}^{2}\right)$ and Marula $\left(0.06 \mathrm{~km}^{2}\right)$. We were not able to do a complete census of the reserve because of lack of time and resources, so we focused on areas where home ranges had been identified in a previous study in order to get an adequate sample size (Tatman et al., 2000).

Ten control plots of the same size $(100 \mathrm{~m} \times 100 \mathrm{~m})$ but lacking bedding sites were randomly positioned as follows: two control plots in Lokichogio, two in Marula and the remaining six in Zebra. If any part of the plot overlapped with a bedding plot or if a bedding site was found in the plot, then the next randomly selected site was used.

\section{Characteristics of the bedding and control plots}

We calculated density estimates using the T-square nearest neighbour density estimate for the two dominant tree species in the reserve, Euclea divinorum and Acacia drepanolobium (Krebs, 1999). We tested for spatial pattern of both tree species using the Hines test statistic and used the compound measure for the T-square procedure to estimate the final density estimates. The compound measure is more robust to spatial patterns that are not randomly distributed and provides an unbiased estimator of density in moderately clumped patterns (Byth, 1982). Where the number of trees was very low, direct counts were made during the transect walks (Byth, 1982).

We divided each bedding and control plot into ten equidistant $100 \mathrm{~m}$ transects. We recorded all buffalo dung, elephant dung, rhino middens, and bedding sites within $5 \mathrm{~m}$ on each side of the transect. Rhino middens are specific areas where rhinos excrete their dung and urine (Tatman et al., 2000). 


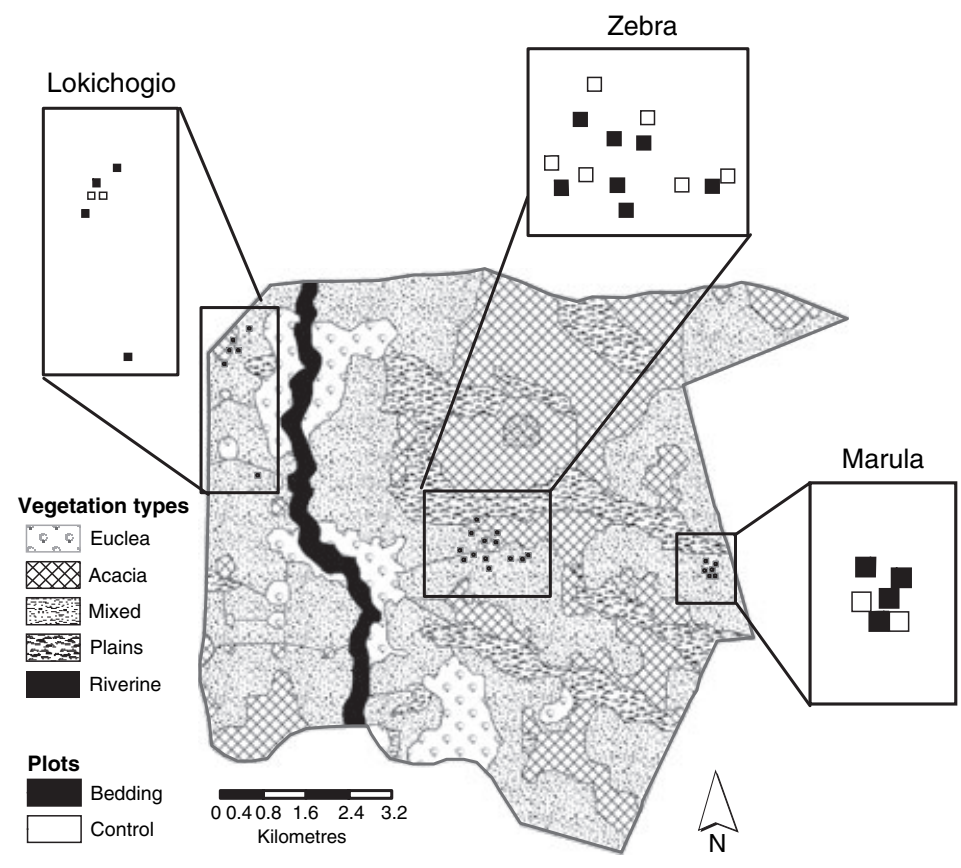

Fig 1 Outline map of bedding and control plots from the three areas of study and the vegetation types found within Sweetwaters Reserve, Kenya as of 2000
We used a Proc GLM statement in SAS to calculate a two-factor ANOVA with treatment (bedding versus control) and region (Lokichogio, Marula and Zebra) as well as interaction effects (SAS Institute Inc., Cary, NC, U.S.A.). We used the type III sums of squares and the GLM procedure because of the unbalanced design of our data (Scheiner \& Gurevitch, 2001). If differences were detected, mean separations were conducted with the least squares distance test (LSD). The Shapiro-Wilk's test of normality was used on all variables.

A discriminant function analysis was then used to determine which variables or combination of variables could be used to separate the control and bedding plots. A stepwise selection procedure was carried out which entered variables that minimized the Wilks lambda criterion at each step until nonsignificant.

\section{Characteristics of the bedding sites}

We used ArcGIS 9.0 to map the vegetation in Sweetwaters reserve as well as the bedding and control plots (ESRI, Redlands, CA, U.S.A.). We calculated the distance from the center of each bedding and control plot to the nearest water source. We then calculated the amount of available vegetation types in the reserve and summarized the vegetation types found at the bedding sites and an equal number of random points.
We used a G-test to determine if bedding sites had a different vegetative composition than what was available in the reserve. We used a G-test because it is more robust to counts $<5$. We also determined if the random points and bedding sites had different vegetation types using the G-test to see if the pattern of selection was random. We utilized a Bonferroni adjustment to calculate $90 \%$ confidence intervals to determine selection for vegetation types.

Recordings were made of tree height and width for each tree immediately surrounding the bare earth, bare earth length and width, grass cover, percent shade on the bare earth, and distance of each tree to the center of the bare earth. All measurements were done with a $20 \mathrm{~m}$ tape measure except for tree height, which was measured with a klinometer. Many of the bedding sites contained multiple bare earth patches separated by trees so each bare earth patch was considered a bed. Thus, a bedding site could have multiple beds.

All tracks, dung, or browse of rhino and elephant were also recorded. Rhino browse is characterized by a clean cut of the main stem on the branches of trees (Oloo, Brett \& Young, 1994) at the shoulder height of a rhino, c. $1.7 \mathrm{~m}$ (Kingdon, 1997). Elephants cause more extensive damage and the bark is left hanging in strips (Birkett, 2002). Although browse was frequently recorded, its extent may actually have been underestimated because of the density of vegetation surrounding the bedding sites. 
Descriptive statistics were evaluated for all measurements taken at the bedding sites. Normality of each of the variables was tested with the Shapiro-Wilk's test of normality. A Kruskal-Wallis test was then used to find any differences between each of the variables in the three areas.

The density of trees surrounding the bedding site was calculated using the number of Acacia or Euclea trees and the area of the bare earth for the density estimate. This was then compared with the density estimates of the bedding and control plots using a Kruskal-Wallis test. The Shapiro-Wilk's test of normality was used to assess normality of all three density estimates.

\section{Results}

\section{Characteristics of bedding sites}

We measured a total of 59 rhino beds in 39 bedding sites. Rhino browse was the most abundant feature, found in $66.7 \%$ of the bedding sites. Elephant dung was the second most encountered feature, found in $23.1 \%$ of the sites. The average number of trees at each bedding site was 8.85 $(\mathrm{SD}=0.56)$ with six different species identified. Euclea comprised $64 \%$ of the trees, which was the most abundant tree species. Seven bedding sites were completely surrounded by Euclea species.

The Kruskal-Wallis test showed significant differences between the three areas for Euclea, tree width, bare earth length and bare earth width (Table 1). There were no significant differences for Acacia, tree height, distance to the bare earth, grass cover and canopy cover (Table 1).

The G-test between the bedding site vegetation compared with the available vegetation in the reserve was significantly different $(P<0.001)$. The rhinos were selecting for the mixed Euclea/Acacia vegetation type for their bedding sites and selecting against Euclea only, Acacia only, riverine, and grassland vegetation. The random points were not significantly different from what was available and there was no selection occurring $(P=0.066)$. The random points and the bedding sites were significantly different in composition of vegetation types $(P=0.001)$.

\section{Characteristics of the bedding and control plots}

The ANOVA showed that Euclea was the only nonsignificant variable for both the treatment and control area (Table 2). Acacia was significantly different between the three areas and using the LSD test we found that Lokichogio was different from the other two areas (Lokichogio: mean $=1887.1$; Marula mean $=494.6$; Zebra mean $=$ 423.9). Elephant and buffalo dung were significantly different for treatment with both showing more dung in the bedding plots than in the control plots. The distance to water showed a significant difference between all areas with shorter distances associated with Marula and longer distances for Lokichogio (Marula mean $=82.7 \mathrm{~m}$; Zebra mean $=227.01 \mathrm{~m} ; \quad$ Lokichogio $\quad$ mean $=1026.5 \mathrm{~m})$. There was an interaction effect for middens, so pinpointing the source of variation for middens was not possible.

Table 1 Mean and standard deviations for each of the variables taken at the bedding site in the Lokichogio, Marula and Zebra areas (unit of measurement is given in parentheses following the name of each variable)

\begin{tabular}{|c|c|c|c|c|c|c|c|}
\hline & \multicolumn{2}{|c|}{ Lokichogio $(\mathrm{n}=15)$} & \multicolumn{2}{|c|}{ Marula $(\mathrm{n}=15)$} & \multicolumn{2}{|c|}{ Zebra (n = 29) } & \multirow[b]{2}{*}{$P$-value } \\
\hline & Mean & SD & Mean & SD & Mean & SD & \\
\hline Acacia (count) & 0.054 & 0.101 & 0.024 & 0.066 & 0.039 & 0.100 & 0.686 \\
\hline Euclea (count) & 0.341 & 0.231 & 0.803 & 0.214 & 0.707 & 0.280 & $<0.001^{*}$ \\
\hline Tree height (m) & 3.846 & 0.70 & 3.859 & 0.928 & 3.429 & 0.813 & 0.148 \\
\hline Tree width (m) & 3.716 & 0.543 & 3.288 & 1.043 & 2.839 & 0.711 & $0.003^{*}$ \\
\hline Bare earth length (m) & 3.08 & 0.627 & 2.667 & 0.609 & 3.176 & 0.594 & $0.034^{*}$ \\
\hline Bare earth width (m) & 1.533 & 0.417 & 1.613 & 0.544 & 2.197 & 0.537 & $<0.001^{*}$ \\
\hline Distance to bare earth (m) & 2.50 & 0.667 & 2.114 & 0.525 & 2.416 & 0.303 & 0.071 \\
\hline Grass cover $(\%)$ & 10.133 & 14.98 & 24.28 & 18.59 & 14.32 & 19.77 & 0.110 \\
\hline Canopy cover (\%) & 58.33 & 39.58 & 61.67 & 40.03 & 38.10 & 36.75 & 0.097 \\
\hline
\end{tabular}

*Variables are with significant $P$-values (Kruskal-Wallis test statistic). 


\begin{tabular}{llllc}
\hline & $\begin{array}{l}\text { Treatment } \\
\text { (control, bedding) }\end{array}$ & $\begin{array}{l}\text { Area (Lokichogio, } \\
\text { Zebra and Marula) }\end{array}$ & Interaction & Overall \\
\hline Acacia & 0.771 & $<0.001^{*}$ & 0.919 & $0.001^{*}$ \\
Euclea & 0.441 & 0.059 & 0.405 & 0.109 \\
Elephant dung & $0.003^{*}$ & 0.294 & 0.398 & $0.013^{*}$ \\
Buffalo dung & 0.068 & 0.465 & 0.889 & $0.047^{*}$ \\
Distance to water (m) & 0.936 & $<0.001^{*}$ & 0.856 & $<0.001^{*}$ \\
Midden & $0.003^{*}$ & 0.223 & $0.050^{*}$ & $0.004^{*}$ \\
\hline
\end{tabular}

Table $2 P$-values associated with the twofactor ANOVA with treatment (control versus bedding plot) and area (Lokichogio, Marula and Zebra) as the factors along with any interaction effects

*Significant values.

Table 3 Density estimates and standard deviations for Acacia and Euclea tree species in bedding sites, bedding plots and control plots

\begin{tabular}{llllll}
\hline & \multicolumn{2}{l}{ Acacia } & & & \multicolumn{2}{l}{ Euclea } \\
\cline { 2 - 3 } \cline { 6 - 7 } & Mean & SD & & mean & SD \\
\hline Bedding site & $0.05 \mathrm{~m}^{-2}$ & 0.15 & & $0.78 \mathrm{~m}^{-2}$ & 0.65 \\
Bedding plot & $0.09 \mathrm{~m}^{-2}$ & 0.09 & & $0.04 \mathrm{~m}^{-2}$ & 0.04 \\
Control plot & $0.07 \mathrm{~m}^{-2}$ & 0.07 & & $0.02 \mathrm{~m}^{-2}$ & 0.03 \\
\hline
\end{tabular}

The discrimant analysis showed that the control and bedding plots could be statistically separated $\left(\chi^{2}=9.449\right.$; $P=0.002$; Wilk's lamda $=0.657$ ) and the presence of elephant dung was the only variable selected for analysis (discriminant coefficient $=1.00$ ). Out of 25 plots, nineteen were correctly classified as having bedding sites in them using elephant dung; one plot was incorrectly assigned to the bedding plot and five plots were incorrectly assigned to the control plot. This means that $76 \%$ of the time, a plot will be correctly identified as a bedding plot based on the presence of elephant dung.

Tree data

A Kruskal-Wallis test showed that the densities of Euclea and Acacia were significantly different for the bedding site, control plots and bedding plots $(P<0.001$ for both species). There was a higher density of Euclea trees in the bedding site compared to both the control and the bedding plots (Table 3). Acacia showed the opposite pattern with a slightly higher density of trees in the bedding and control plots compared with the bedding sites.

\section{Discussion}

Although specific inferences regarding a model predicting bedding sites can not be made, patterns can be seen in the descriptive statistics. Bedding sites contained more Euclea than Acacia and the average tree heights were at least twice as tall as the average height of a rhino regardless of area. In addition, canopy cover provided at least $38 \%$ shade on the bare earth patch. These characteristics of a bedding site indicate that Euclea trees are important for protecting the rhinos from the sun. Although Lokichogio had the least number of Euclea trees in the bedding site, the tree width was greater than for the other areas. This could indicate that regions lacking large numbers of Euclea have wider trees so they can still provide adequate shade with fewer trees.

The bedding and control plots had a higher density of Acacia than Euclea, whereas the bedding site had more Euclea than Acacia. The rhinos were also selecting for mixed Euclea/Acacia vegetation, but the bedding sites seem to be primarily made up of Euclea trees. It may be useful to identify these clumps of Euclea in areas with high densities of Acacia to initially detect bedding sites in the mixed shrubland of Sweetwaters. This could provide an easier method of surveying and monitoring the bedding sites.

There were three significantly different features between control and bedding plots: elephant dung, middens and buffalo dung. Elephant dung was the only variable used in the discriminate analysis to separate bedding and control plots. In addition, $23 \%$ of the bedding sites had elephant dung and $13 \%$ had elephant browse within them. This may be either an indication of a positive association between the two species or, perhaps more likely, a preference for the same habitats.

During the game count at Sweetwaters in 1998, there were 95 elephants indicating a density of about 1 elephant $\mathrm{km}^{-2}$. The current density is around 0.500.65 elephants $\mathrm{km}^{-2}$ because of the removal of elephants during the summer of 2001. This high density of elephants and possible overlap of rhino and elephant habitat as shown in our bedding plots could be a factor in rhino habitat selection. It could also be causing damage to trees 
in the bedding site. Further investigation into the damage caused by elephants at the bedding site in particular is necessary to answer the question about specific damage to the bedding sites.

Pellew (1983) found that elephants were linked to declines in woodland canopy cover and this transformation to grassland negatively affects other species including black rhino (Estes, 1991). Reduced canopy cover could decrease the quality of rhino bedding sites and the suitable habitat available. Measurements of the canopy cover in bedding sites could be used as specific indicators for the quality of habitat because of their repetitive use by black rhinos. This would enable small reserves to monitor tree damage focusing on the effects to rhino habitat. If these sites are maintained with little tree damage, the reserve can likely support a higher density of rhino.

Protection within reserves is likely to be the most viable method of conserving rhinos. However, smaller reserves may require management intervention to counter the effects of restricted dispersal on demography and behaviour (Rachlow et al., 1999). With the declining space for wildlife in Kenya and the push towards small fenced reserves for black rhinos, there will likely be an increase in conflict between species competing for reduced resources. This could have a detrimental impact on bedding sites, which may eventually lead to a decrease in the number of black rhinos at Sweetwaters.

\section{Acknowledgements}

We would like to thank the staff at Sweetwaters Research Centre for their help and the Kenya Wildlife Service for providing the permission to do this work. We would also like to thank D. Downing, J. Eales and E. Astbury for their assistance in the field and K. Searle for advice on this paper. We also thank B. Stevens-Wood for direction and guidance on this project. We especially thank G. Perry for his advice and assistance on earlier drafts of this paper.

\section{References}

BERGER, J. (1994) Science, conservation, and rhinos. J. Mammal. 75, 298-308.

BirketT, A. (2002) The impact of giraffe, rhino and elephant on the habitat of a black rhino sanctuary in Kenya. Afr. J. Ecol. 40, 276-282.

Вүтн, K. (1982) Robust distance based intensity estimates. Biometrics 38, 127-135.

Estes, R.D. (1991) The Behavior Guide to African Mammals. University of California Press, Berkeley.

Hall-Martin, A.J. \& Penzhorn, B.L. (1977) Behaviour and recruitment of translocated black rhinoceros, Diceros bicornis. Koedoe 20, 147-162.

JouberT, E. \& ELoff, F.C. (1971) Notes on the ecology and behaviour of the black rhinoceros Diceros bicornis in South West Africa. Madoqua Ser. 1, 5-53.

KingDon, J. (1997) The Kingdon Field Guide to African Mammals. Academic Press, London, U.K.

KreBs, C.J. (1999) Ecological Methodology. Addison-Welsey Educational Publishers, Menlo Park, CA, U.S.A.

Oloo, T.W., BRetT, R. \& Young, T.P. (1994) Seasonal variation in the feeding ecology of black rhinoceros (Diceros bicornis L.) in Laikipia, Kenya. Afr. J. Ecol. 32, 142-157.

Pellew, R. (1983) The impacts of elephants, giraffe, and fire upon the acacia-tortillas woodlands of the Serengeti. Afr. J. Ecol. 21, 41-74.

Rachlow, J.L., Kie, J.G. \& Berger, J. (1999) Territoriality and spatial patterns of white rhinoceros in Matobo National Park, Zimbabwe. Afr. J. Ecol. 37, 295-304.

SCHeINER, S.M. \& GuREviTch, J. (2001) Design and Analysis of Ecological Experiments. Oxford University Press, New York, NY, U.S.A.

SCHENKel, R. \& SCHENKel, L. (1969) Ecology and Behaviour of the Black Rhinoceros (Diceros bicornis L.). Verlag Paul Parcy, Berlin.

STEvens-Wood, B. (2000) Wildlife Conservation in Enclosed Reserves. A draft Proposal for Collaborative Research in Kenya. Manchester Metropolitan University, Manchester, UK.

Tatman, S.C., Stevens-Wood, B. \& Smith, V.B.T. (2000) Ranging behaviour and habitat usage in black rhinoceros, Diceros bicornis, in a Kenyan sanctuary. Afr. J. Ecol. 38, 163-170.

(Manuscript accepted 30 April 2006)

doi: $10.1111 / \mathrm{j} .1365-2028.2006 .00657 . \mathrm{x}$ 